\title{
Research on the Transformation of Teaching and Research Form of Professional Teachers in Blended Learning at Colleges and Universities - Taking the Java Programming Course as an Example
}

\author{
Xiuying Wu*, Lingjia Chen \\ Jiangxi Environmental Engineering Vocational College, Ganzhou 341000, Jiangxi Province, China \\ *Corresponding author: Xiuying Wu, 57255626@qq.com
}

\begin{abstract}
In view of the current situation that offline teaching is the main mode of teaching Java Programming in higher vocational schools, this paper introduces the online and offline hybrid teaching method and expounds it from the aspects of blended learning design, teaching organization, and implementation. At the same time, combined with the characteristics of blended learning, this paper proposes that under the new mode, teachers should actively change the form of teaching and research, the teaching mode, and the role of teachers, take students as the center, and build an independent and effective classroom.
\end{abstract}

Keywords: Java Programming; Blended learning; Teacher's role; Teaching and research form

Publication date: December 2021; Online publication: December 23, 2021

\section{Necessity of blended learning in Java Programming}

Java Programming is a professional course for computer related majors in higher vocational colleges. It mainly teaches the thinking and methods of object-oriented programming, and then applies Java language to object-oriented programming to help solve real life problems.

At present, the mode of teaching Java Programming in universities is mainly through offline teaching. The whole teaching process follows the traditional mode of preview before class, explanation in class, and review after class. The learning situation has been analyzed and several problems have been found.

(1) Students have poor self-discipline and weak awareness of autonomous learning. Students' learning initiative is not strong enough, and the pre class preview work is not in place, resulting in the insufficient grasp of key and difficult points and a poor listening effect ${ }^{[1]}$.

(2) There are many courses but a short learning time. Java Programming is a basic course with strong practicality. There are many courses, but there are only minimal class hours, so it is difficult to finish all the contents.

(3) The course has a wide range of knowledge. In addition to the content related to program design, it also involves network service access technology and database technology. Teachers also have to introduce extended contents, such as network and protocol, Structured Query Language (SQL) statement, and so on. 
(4) The method of cultivating java development skills is single. Java is a very practical course, which requires students to carry out a lot of programming practice. The learning process is mainly concentrated in the classroom. It is difficult to effectively improve students' development skills only by classroom exercises and a small amount of homework.

(5) The communication between teachers and students is untimely. It is difficult for teachers to effectively supervise the time after class, while for students, it is difficult for them to obtain timely and effective guidance when they encounter problems. With the increase of content, the difficulty of the course also increases; the students face difficulties in accepting, lack self-confidence, and give up easily.

Due to the lack of mandatory constrains and timely interaction with students, the current massive open online course (MOOC) cannot replace the traditional classroom. Therefore, it is necessary to explore the new online and offline hybrid teaching mode based on the advantages of MOOC and traditional classroom teaching ${ }^{[2]}$.

\section{Advantages of blended learning}

As an open teaching resource, online teaching achieves many purposes, such as classroom reproduction, convenient knowledge acquisition, and open communication. It effectively makes up for the shortcomings of offline teaching. Therefore, it is an important idea of the curriculum reform to organically combine online teaching with traditional teaching by using blended learning.

The focus of object-oriented programming courses is to cultivate students' programming skills, so computer practice is a very important link for students. Therefore, the course has adopted blended learning, which gives full play to the advantages of both online and offline methods as well as truly implements student-centered teaching.

Compared with the traditional mode of teaching, blended learning has several advantages.

(1) It extends the classroom, making learning more flexible. Students are able to learn anytime and anywhere. They have the opportunity to preview before lessons, repeatedly watch videos after their classes, and repeatedly learn the difficult parts of the course to achieve in-depth understanding.

(2) Its learning resources are rich. The learning platform provides rich teaching resources, including course syllabus, teaching videos, courseware, exercises, tests, discussions, etc. Students can choose different resources for learning according to their learning habits.

(3) It ensures a smooth and timely communication between students and teachers. Open communication is encouraged before, during, and after lessons. Teachers and students can help each other in solving the questions and doubts faced. This would not only increase their interest of learning but also consolidate knowledge; in addition, it would help teachers understand the students' learning situation in a timely manner.

(4) It solves the issue of "many content points but insufficient class hours." Learning tasks can be designed and students can be asked to complete them after lessons. Classroom teaching will be used to focus on the key and difficult points, so as to effectively solve the issue of insufficient class hours.

\section{Design of Java Programming blended learning}

\subsection{Network teaching platform}

The network teaching platform includes Intelligent Chinese Vocational Education, Learning Link, and other learning platforms. Through learning platforms, teachers would be able to upload their teaching resources 
anytime and anywhere, edit chapter contents and set task points, give assignments and tests, communicate with their students in real time, as well as supervise their students' learning. Through Learning Link, students can also learn the chapter content anytime and anywhere, complete the tasks assigned by their teachers, submit their homework, conduct online tests, as well as communicate with their teachers and other students in real time. The platform effectively integrates pre-class preview, explanation and discussion of key and difficult points during lessons, as well as Q \& A thereafter. Offline teaching includes classroom, laboratory, etc.

\subsection{Teaching contents}

The teaching contents are Java basic syntax and object-oriented, including classes and objects, method overloading and recursion, encapsulation, inheritance and polymorphism, interfaces, exceptions, common classes in Java, collections, I/O flows, graphical user interfaces, Java Database Connectivity (JDBC), multithreading, as well as network programming.

\subsection{Course objectives}

Through this course, students should achieve several objectives.

(1) Ideological and political objectives. Students would come to know and abide by the professional ethics and norms of computer professionals in the process of software development as well as establish correct life values and patriotism.

(2) Knowledge level objectives. Students would be able to use object-oriented analysis methods to carry out system analysis, master Java syntax, use Java language to program, and carry out simple visual programming.

(3) Skill level objectives. Students would be able to use Java language to solve complex engineering problems in computer software development, apply object-oriented analysis methods for effective analysis, and effectively communicate with others as well as have a sense of cooperation ${ }^{[3]}$.

\subsection{Assessment and evaluation}

The evaluation of online and offline blended learning mainly focuses on the assessment of students' learning process, including weekly online preview, participation in discussion, and the completion of tests, online tests, practical tasks through cooperation, and project tasks in after-school promotion. It also includes the cumulative record of students' learning status and results, class learning analysis based on students' weekly completion, praising students with outstanding performance, and timely warning those students with poor learning status. Teachers should determine the problems according to the learning situation of that week, timely adjust the online and offline course content for the following week, constantly improve their teaching ability and students' ability in autonomous learning as well as cooperative learning and meet the teaching objectives of the course ${ }^{[2]}$.

This course has adopted the methods of "process assessment + final examination" and "online assessment + offline assessment," with an increase of $10 \%$ of online learning tasks and $10 \%$ of online questions and discussions. The composition of the scores is shown in Table 1. 
Table 1. Score composition and proportion

\begin{tabular}{|c|c|c|c|}
\hline \multicolumn{2}{|c|}{ Composition of scores } & \multicolumn{2}{|c|}{ Proportion } \\
\hline - & 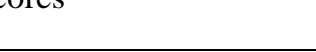 & Traditional teaching & Blended learning \\
\hline Attendance & \multirow{6}{*}{$60 \%$ of average score } & $10 \%$ & $10 \%$ \\
\hline Online learning tasks & & - & $10 \%$ \\
\hline Online questions and discussions & & - & $10 \%$ \\
\hline Classroom performance & & $10 \%$ & $10 \%$ \\
\hline Homework after class & & $20 \%$ & $10 \%$ \\
\hline Experiment & & $20 \%$ & $10 \%$ \\
\hline \multicolumn{2}{|c|}{ Final exam } & $40 \%$ & $40 \%$ \\
\hline
\end{tabular}

\subsection{Organization and implementation}

\subsubsection{Pre-class}

The pre-class link is mainly for teachers to upload learning videos, pre-class learning tasks, key and difficult knowledge points, tests, subjects for discussion, etc. to the learning platform, in order to assist students in learning, discuss, and leave messages on the platform for online preview. Teachers would then record the questions raised by students in the comment area and provide the relevant answers and feedback. On this basis, teachers would also analyze the learning situation and dynamically adjust the course teaching plan.

\subsubsection{In class}

Teachers mainly explain the important and difficult knowledge point in class, deepen students' understanding of difficult knowledge points, summarize general knowledge, expand appropriately, and improve the students' knowledge structure. The classroom is dominated by teacher-student interaction and among students themselves to improve their self-study ability.

\subsubsection{After class}

The cultivation of students' programming skills is mainly achieved through practical tasks. Therefore, teachers should assign relevant practical tasks after explaining the theoretical knowledge on a subject in order for students to review and consolidate their knowledge. Considering the diversified characteristics of higher vocational students, the homework for students should be divided into three categories: basic, advanced, and extended tasks according to the level of difficulty. Students can complete the assigned task based on the actual situation and put forward the difficult points in the forum or group chat. Teachers should summarize and reflect, answer the questions, and sum up their teaching experience, in addition to taking part in appropriate extracurricular development.

\subsection{Teaching interaction}

In blended learning, teaching interaction is an important means to effectively solve students' learning problems. In the process of blended learning, teachers and students make full use of various interactive tools or platforms to interact frequently, effectively solve students' problems in learning, improve their interest, enthusiasm, and initiative, as well as improve students' practical skills. In addition to face-to-face interactive communication, chat tools are often used, such as discussion post, QQ, and WeChat in learning links to interact. 


\section{Key points in hybrid teaching design}

(1) When recording videos, teachers should not only explain the knowledge points but also explain classic cases and carry out relevant exercises together. When teaching coding, teachers should be able to type the code by hand, explain the code design ideas and precautions in the process of typing out the code, and encourage students to follow, so that students will have a stronger sense of immersion and can better keep up with the teacher's rhythm.

(2) When designing learning tasks, teachers should take into account the differences in students' acceptance as well as design basic questions, advanced questions, and extended questions. Students with better learning ability should be asked to become the leader of the learning group.

(3) For online homework, tests, and other evaluation methods, students tend to copy. This challenges the fairness and integrity of these evaluation methods, thus urging the continuous exploration and the reform of the evaluation mechanism to form an online and offline method guaranteeing the fairness in evaluation.

(4) When explaining about programming, teachers should skillfully integrate ideological and political goals. Through the safety of data and code in programming, teachers can extend the education to professional ethics and norms of software developers, so as to cultivate correct life values and noble patriotism among students as well as to encourage students to keep improving, innovating, and pursue excellence.

(5) For innovative and exploratory students, diversified and personalized counseling can be carried out to fully stimulate their initiative and interest in learning. At the same time, combined with the professional studio system, teachers can consciously select excellent students, urge them to learn and expand their knowledge, as well as encourage them to participate in various competitions, such as Innovation Cup, Blue Bridge Cup, etc. ${ }^{[4]}$.

Blended learning combines face-to-face classroom teaching of Java Programming with network classroom teaching, realizes real-time and effective communication, compensates for the lack of class hours, eliminates the disconnection between teaching and learning, fully mobilizes students' learning interest, improves the effect of classroom teaching, and promotes students' learning skills. Its teaching method integrates courseware, video, discussion, coding, and other forms; in addition, it pays more attention to students' learning process and learning interaction in teaching evaluation. The evaluation of students' curriculum learning by teachers includes the online self-learning process and offline practice process. The blended mode of student-centered and teacher-student interaction is more in line with the requirements of the basic courses in Java Programming.

\section{Transformation of teachers' roles and tasks under blended learning}

Compared with the traditional role of teachers as knowledge imparters, blended learning requires the integration of face-to-face learning and e-learning, personalized rhythm and cooperative learning, as well as real-time evaluation and process evaluation. Under this teaching mode, teachers need to change the traditional single role and become the providers of personalized learning content, the supervisors and guides of online learning, the organizers of face-to-face classroom teaching, as well as the evaluators of learning effect, so as to maximize the advantages of the internet teaching platform and help to improve the learning effect of students.

Students can make full use of the teaching resources provided on the network platform to study independently, find problems, and explore independently; At the same time, teachers should not repeat the 
knowledge points included in the online platform but focus on helping students to solve problems according to the problems put forward by the students, so as to further consolidate their knowledge and improve their ability. It changes the teaching-centered traditional classroom and builds up independent colleges and universities. Teachers are not simply the imparters of knowledge or people who only teach book knowledge, but they are the supporters who strive to create a suitable learning environment and condition for the students; in addition, they are the partners of students in activities and guides who steer the activities in the right direction and lead students toward the curriculum objectives. An autonomous and efficient classroom includes the following basic links: independent preview - group exploration - presentation report evaluation feedback. Under the hybrid teaching method, the role of teachers has greatly changed.

\subsection{Teachers are rich providers of online learning materials in the preview stage}

In the independent preview stage, teachers are required to design a guidance plan for learning and guide students to learn and practice, clarify goals, and come prepared to classes ${ }^{[5]}$. Preview can be completed before and during class (5-10 minutes). At this stage, teachers should break the knowledge system of the original teaching materials according to the training objectives of applied talents and class hours, select teaching contents in consideration of the needs of the students' future work, and ensure that students are competent enough. Secondly, there should be a systematic and comprehensive planning for curriculum resources; in addition, the online and offline credits and class hours should be reasonably arranged. Thirdly, teachers should master the basic technical requirements of network knowledge and micro course production through training and self-learning. High-quality micro course resources should be provided with the help of schools and teacher teams.

Therefore, teaching and educating people in the traditional sense is far from enough under the background of the information age. Teachers must change themselves and become comprehensive talents with high-level technical knowledge. Network knowledge and micro course making are the basic skills that future teachers must master. In daily teaching, it is necessary to strive to achieve improvement in the academic level, teaching skills, and information technology through participation in training and autonomous learning.

\subsection{Teachers are supervisors and guides for online learning}

Students learn independently by watching video materials such as micro classes and micro movies. They control and adjust their learning progress according to their own levels and acceptance. On the other hand, students can discuss the problems and difficulties they encounter in learning with their classmates online or ask their teachers questions. The knowledge points that are still unsolved can be recorded and solved during lessons.

In regard to the problems or questions raised by students, teachers should give timely and specific feedbacks and solve them. Autonomous learning does not refer to a free and loose learning. Students' learning state, learning process, and learning effect are inseparable from teachers' active guidance, timely participation, and appropriate supervision. At the same time, in the process of tutorship and guidance, teachers should guide students how to find information as well as cultivate the learning ability of independent thinking and active exploration. In short, in order to benefit the learning status of students, teachers should supervise, guide, and correct frequently as well as introduce process evaluation mechanisms to promote online learning among students.

\subsection{Teachers are organizers of face-to-face classes}

In face-to-face classes, teachers are responsible for organizing, guiding, promoting, and supervising 
activities, such as group discussion and project display.

In regard to the group inquiry link, through means of "students teaching students, students helping students, and teachers helping students," group cooperative learning can be effectively carried out to solve the typical questions raised by students, preset by teachers, and put forward during classes, so as to make full preparations for the display of interaction.

The presentation and reporting link requires students to share their thoughts through competition, questioning, supplement, debate, and evaluation. Teachers listen, sort, advice, and comment according to the teaching objectives and carry out targeted learning guidance.

Through group report and display, self-learning achievements can be detected, feedbacks and records can be made, and key and difficult points in the students' online learning platform can be classified. One part can be solved by students through group discussion, while the other part in terms of difficult knowledge points can be explained more in depth by teachers.

After lessons, as organizers of classroom teaching, teachers should give timely feedbacks to their teaching, timely adjust and improve their teaching methods according to different teaching contents, carefully design teaching links, mobilize students' enthusiasm, and encourage students to cultivate their love for learning and to learn effectively.

\subsection{Teachers are the evaluators of the learning effect}

Evaluation feedback is not only an important link to test the degree and effectiveness of problem solving but also reflects on the learning process and learning effect.

Teachers should divert their attention from examination results to the learning process and form a more scientific and quantitative evaluation for the students. Teachers also need to improve their ability from traditional paper inspection. For example, they need to skillfully use the network platform as well as participate in and monitor the whole learning process of students with the help of the data and information provided by the platform, so as to obtain scientific evaluation.

The automatic scoring system can be introduced into the curriculum evaluation system. Students can practice continuously, submit homework repeatedly, urge self-learning in continuous improvement through their own efforts, review the old and learn the new, aa well as further improve themselves. Teachers should synchronize with the automatic scoring system, participate in the evaluation, and give immediate suggestions and feedbacks to the learners. At the same time, mutual evaluation among students can be added to the system to ensure a more objective evaluation and avoid a dominant evaluation by teachers ${ }^{[6]}$.

\section{Use research to promote change, develop the team, and improve information retrieval skills}

First, under blended learning, there are countless resources on the network. Teachers need to screen highquality resources to serve their own classroom. Therefore, teachers need to have strong information retrieval and information screening skills.

Secondly, blended learning requires teachers to provide a large number of teaching resources, such as micro class resources, courseware resources, and syllabus. It is difficult to complete the task singlehandedly; instead, it requires team cooperation. The team should be developed through research and change, while the lesson preparation should be changed from individual to collective. The team members should give full play to their advantages and work with each other. Core teachers should play a leading role, take the lead in demonstration classes by using new teaching methods, constantly discuss and revise, establish a teaching mode that is suitable for their majors and more operations, as well as hold teaching and research exchange meetings more often to share their experiences and practices, so as to promote team building and jointly create high-quality course resources. 
Blended learning would become the mainstream teaching mode in the future. Teachers should change their roles, give full play to the advantages of online teaching, pay attention to the complementary advantages of online teaching and classroom teaching, constantly improve their ability in teaching, and learn from each other. It is also necessary to give full play to the organizational guidance and supervision role of teachers, encourage and participate in teaching, allow students to master learning and research methods in autonomous learning and research, as well as improve learning ideas, so as to better improve students' cognition and learning effect.

\section{Funding}

This study was supported by the General Project of Ganzhou Social Science Research in 2021 - Research on the Transformation of Teaching and Research Form of Professional Teachers in the Blending Learning Mode of Colleges and Universities - Taking the Course "Java Programming" as an Example (Project Number: 2021-028-0323).

\section{Disclosure statement}

The authors declare that there is no conflict of interest.

\section{References}

[1] Wang Y, 2021, A Preliminary Study on the Implementation of Blending Learning in the Course of C Language Programming. Technology Wind, 2021(10): 43-45.

[2] Lai H, 2021, Research on Online and Offline Blending Learning Mode - A Case Study of Java Programming Basic Course in Vocational Colleges. Occupation, 2021(10): 52-54.

[3] Peng Z, 2021, Practice of Blending Learning in Object-oriented Programming Course. Journal of Fujian Computer, 2021(10): 136-138.

[4] Yang W, Qiu L, 2021, A Blending Learning Design Based on Teaching-Society-Technology Theory A Case Study of "Principle and Application of Single-chip Microcomputer" Course. Wireless Internet Technology, 2021(08) 149-150.

[5] Ma J, Han X, Cheng J, 2018, A Study on the Design of Blending Learning Activities Promoting Learning Engagement. Tsinghua Journal of Education, 2018(6).

[6] Yao Y, 2019, Transformation of Teachers' Roles and Tasks under Current Blending Learning Mode. Journal of Tianjin College of Commerce, 6(7): 77-80. 